\title{
EINE HEURISTIK ZUR OPERATIVEN PRODUKTIONSPROGRAMMPLANUNG BEI AUFTRAGSORIENTIERTER EINZELFERTIGUNG
}

\author{
Werner Geiger, Universität Bayreuth
}

Bei einer sukzessiv durchgeführten Produktionsplanung und -steuerung erfolgt für gewöhnlich zuerst die Festlegung des Absatz- und Produktionsprogramms. Speziell bei einer kundenauftragsorientierten besteht häufig das Problem, daß bei der Bestimmung des Absatzprogramms die Produktionsressourcen unberücksichtigt bleiben, was zu Schwierigkeiten bei der Termineinhaltung führen kann. Die fehlende Einbeziehung der Produktionspotentiale ist nicht zuletzt auf die Unsicherheit der zukünftigen Nachfrage zurückzuführen.

Im folgenden soll eine Heuristik vorgestellt werden, mit deren Hilfe sich bei Eingängen von potentiellen Kundenaufträgen Entscheidungen über die Auftragsannahme treffen lassen. Im Hinblick auf die unterstellte globale Unternehmenszielsetzung Gewinnmaximierung finden dabei die auftragsbezogenen Merkmale Deckungsbeitrag, Lieferzeit, Produktionsressourconbeanspruchung und Kundenpriorität, als unternehmensbezogene Kriterien die zum E'itscheidungszeitpunkt vorliegenden Kapazitätsauslastungssituationen der einzelnen Produktionsstufen sowie als marktbezogene Größen Erwartungen (Verteilungen) über die zukünftigen Kundenaufträge hinsichtlich Quantität, Deckungsbeiträge und Kapazitätsbedarfsstruktur Berücksichtigung. Durch geringfügige Modifikationen läßt sich das Modell zur Auftragsselektion in ein Verfahren zur Angebotsplanung überführen, das der Ermittlung von Auftragspreisuntergrenzen in Abhängigkeit der Kundenpriorität und der Lieferzeit dient.

Das Verfahren eignet sich speziell für Produktionssituationen, die sich wie folgt kennzeichnen lassen:

- mehrstufiger Produktionsprozeß mit mehreren potentiellen Engpässen

- kein Bevorratungsgrad an Eigenfertigungsteilen

- keine zusammenfassung von durch unterschiedliche Kundenaufträge induzierten Fertigungsaufträgen zu gemeinsamen Fertigungslosen

- reihenfolgeunabhängige Rüstzeiten

Abschließend sollen zur Beurteilung der Leistungsfähigkeit der Heuristik die Ergebnisse (kleinerer) Studien vorgestellt werden. 